\title{
A study on the effects of Product quality, Educational quality, and Service quality of Experimental (practice) teaching aids and manufacturing companies on elementary school teacher's satisfaction and repurchase intention
}

\author{
Ig-Hyeng Cho , Doctoral Student, Dept. Of Knowledge Service \& Consulting, Hansung University, 02876, \\ Seoul, Korea,Cho-ig@hansung.ac.kr \\ *Jung-Wan Hong, Professor, Dept. Of Division of Smart Management Engineering, Hansung University, \\ 02876, Seoul, Korea, jwhong@hansung.ac.kr \\ *Corresponding Author
}

\begin{abstract}
This study aimed to analyze the satisfaction of teachers and their repurchase intention on the product quality, educational quality, and service quality of using Experimental (practice) Teaching Aids (ETA). The purpose of this is to provide guidance to companies in the development of new products and contents, and to give teachers insight through statistical data. The CIT (Critical Incident Technique) which was conducted first, has generated a total of 142 core events. As a result of this, the teachers had negative experiences about product quality, while the positive experiences were about the convenience in the purchase and usage of the product. Also, there were more positive responses to experiences in the service-related part of ETA companies. The second questionnaire was analyzed through empirical analysis that product quality, educational quality, and service quality had a positive (+) effect on teacher's satisfaction, and teacher's satisfaction had a positive (+) effect on repurchase intention, and all research hypotheses were adopted. In particular, service quality was measured by transforming the five-dimensional attributes of the existing SERVQUAL (adding Accessibility items), and this proved to be one of the most important variables. The results of this study can be used as a basic data for the development and distribution of new products and contents for ETA and contents for manufacturing companies. Furthermore, it could be a basis of further research for middle school and high school teachers.
\end{abstract}

Keywords: CIT. Elementary School. Experimental teaching aids. Education. SERVQUAL.

Received: 09.12 .2020

Accepted: 11.01 .2021

Published: 06.02.2021

\section{INTRODUCTION}

The Fourth Industrial Revolution heralds a shift from teacher-oriented learning to student-oriented learning, and the OECD suggests that the concept of student initiative is key to educational reform, presenting a framework for future learning [1]. This movement has been around in the past, and the willingness to change education to a more practical and student-centered environment has driven the use of the education kit in regular education [2]. Also, not only the first-time elementary school teachers lack experience in science, but experienced teachers also feel that they lack the content needed for education [3], turning to education kits to address this [4].

The education kit also has a positive effect on increasing the teacher's confidence in the subject [2] and on increasing student satisfaction and cohesiveness [5].

Specifically, in science subjects where the education kits are most commonly used as teaching aids, these science kits have raised students' interest in science and improved their understanding of the scientific concepts and processes resulting to more productivity and achievement [6]. But in reality, most companies that produce and distribute Experimental (practice) teaching aids (ETA) for domestic education are small, making it difficult to develop teaching aids and educational contents that are safe and suitable for the learning goals of the children.

This paper presents effective guidelines for developing new products and contents for teaching aids firms and gives more insight to teachers to be utilized in education by providing current status and statistical data of ETA. 


\section{Theoretical background}

\subsection{Experimental (practice) teaching tools (ETA)}

In Korea, educational tools are designed mainly for the purpose of education and learning. Moreover, there are various educational media directly used for teaching and learning activities to effectively achieve educational goals, hereby defined as 'science teaching tools' or 'educational teaching aids' [9]. There are also researchers who define teaching aids as tools that are used to materialize learning, make learners intuitive, and effective [18]. In this study, all the teaching aids used in elementary schools will be collectively referred to as Experimental (practice) teaching aids (ETA).

These teaching aids not only determine the quality of education, but are also important for the student's overall development wherein they interact with other peers, improve language development, and be able to have expressive skills, creativity, and exploration skills [3]. These days, schools have separate science laboratories to enable the students conduct various experiments. In fact, most schools in Korea, regardless of school size and number of students, have laboratories. However, although laboratories are important for teaching science, they are not often used [8]. The reason is that most teachers are reluctant to use the laboratories due to various problems such as lack of laboratory room preparation and safety procedures. To improve such circumstance, more and more teachers are using simple ETA in the classroom.

In addition to that, studies have shown that many novice teachers and even experienced teachers are already aware of the insufficient content for science classes, and this results to being wary or are less prepared to teach $[13,14]$. This is also one of the reasons why teachers use science teaching aids in their classrooms.

\subsection{CIT}

The Critical Incident Technique (CIT) is evaluated as having the advantages of qualitative and quantitative research [10].

CIT was developed based on research conducted in the Aeronautical Psychology Program of the Army Aviation Corps during World War II [11], and was recognized as a research technique that is effectively used in areas where consumer reactions must be sensitively accepted [10].

CIT can obtain records of concrete actions from people in an optimal position to make the necessary observation and evaluation. It consists of five steps: (1) General goal setting, (2) plan and specification establishment, (3) data collection, (4) data analysis, (5) data interpretation and report [11].

Among several qualitative research methods, the CIT was chosen in this study with the following reasons: First, CIT is a useful tool for evaluating customer dissatisfaction at service contact points, and the results of CIT provide much more detailed and in-depth understanding than those typical customer satisfaction surveys [12]. Second, it is a useful technique for examining the essence of a phenomenon rather than generalizing a particular phenomenon [10]. Lastly, through the CIT, it has possible to not only grasp what knowledge and what control is being needed, but it also to provides a basis for determining which aspect is more important to a specific type of contact point [12].

\section{Materials and Methods \\ 3.1. Result of CIT}

CIT which has been the first questionnaire used was foremost conducted in order to check whether elementary school teachers are satisfied or dissatisfied with the quality and service of using Experimental (practice) teaching aids (ETA) in their classes. The questionnaire was conducted to 60 in-service elementary school teachers who are mostly in Gyeonggi-do. Of the total number of survey participants, men were slightly more than $55 \%$, and for the age group, participants in their 40 s was accounted the most at $46 \%$. Most of the teachers who answered the questionnaire had more than 10 years (38\%) and over 20 years (37\%) of work experience. The questionnaire mainly asked participants about their best and worst experience in using ETA for a period of one (1) year.

A total of 142 key events (69 positive experiences and 73 negative experiences) was extracted using the CIT, and most of these was about product quality, connectivity with education, and purchase-related events. These contents were then summarized into three 'quality variables' namely: product quality, educational quality and service quality. This has been undertaken with several professional teachers advises from a series of meetings, and is consistent with prior studies conducted.

\subsubsection{Product Quality}

Nam categorized the quality-related parts of the teaching aids into safety, functionality, convenience, design, organization and management [20], and Jeon \& Kim categorized it into performance and convenience, safety, durability, service and accessibility [19]. In this study, the quality-related parts of the 
teaching aids was determined as a product quality variable, and classified into six namely: safety, functionality, convenience, design, economic, and management.

[Figure 1] shows the results of the 142 core events which appeared in the survey using the CIT, that was arranged accordingly to match with the six (6) classifications above. The survey participants answered mostly positive in the experiences related to convenience, however, there were far more negative experiences related to safety, functionality, and economics and in particular, most of the survey participants were dissatisfied with functionality.

In this study, the hypothesis below tries to be established and verified based on the preceding studies above.

H 1: Product quality will have a positive (+) effect on teacher satisfaction.

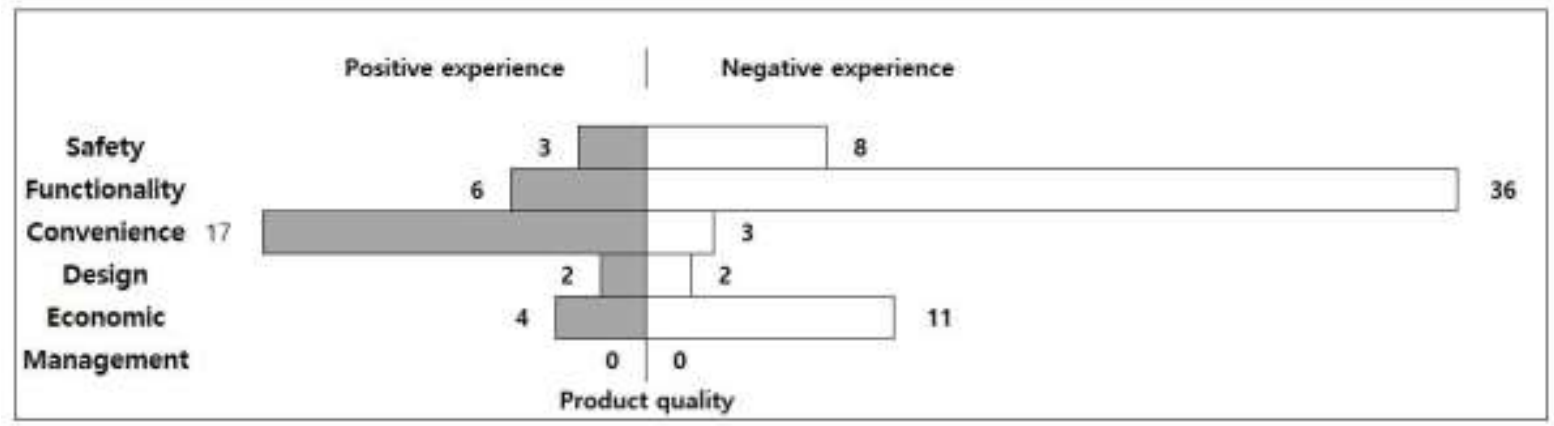

Figure 1. Product Quality

\subsubsection{Educational Quality}

The concept of educational quality presented in this study is different from education service quality. Jeon \& Kim used education-related areas such as 'suitability of curriculum', 'appropriateness of learning developmental stage', and 'applicability to other subjects' without classifying them with product quality areas in a study on the evaluation and analysis of teaching aids [19]. However, Nam classified items such as contents, manuals, usability, creativity, and appropriateness into educational areas, and researched them as separate items from product quality [20]. In this study, based on the preceding studies above, education quality was classified into five items: necessity, suitability, manual, availability, and creativity.

[Figure 2] shows the results of the 142 core events which appeared in the survey using the CIT, that was arranged accordingly to match with the five (5) classifications above.

Most of the survey participants answered positively on experiences related to creativity, which means that the teachers acknowledge that ETA used in schools induce interest, fun, and creativity to students.

In this study, the hypothesis below tries to be established and verified based on the preceding studies above.

H 2: Educational quality will have a positive (+) effect on teacher's satisfaction.

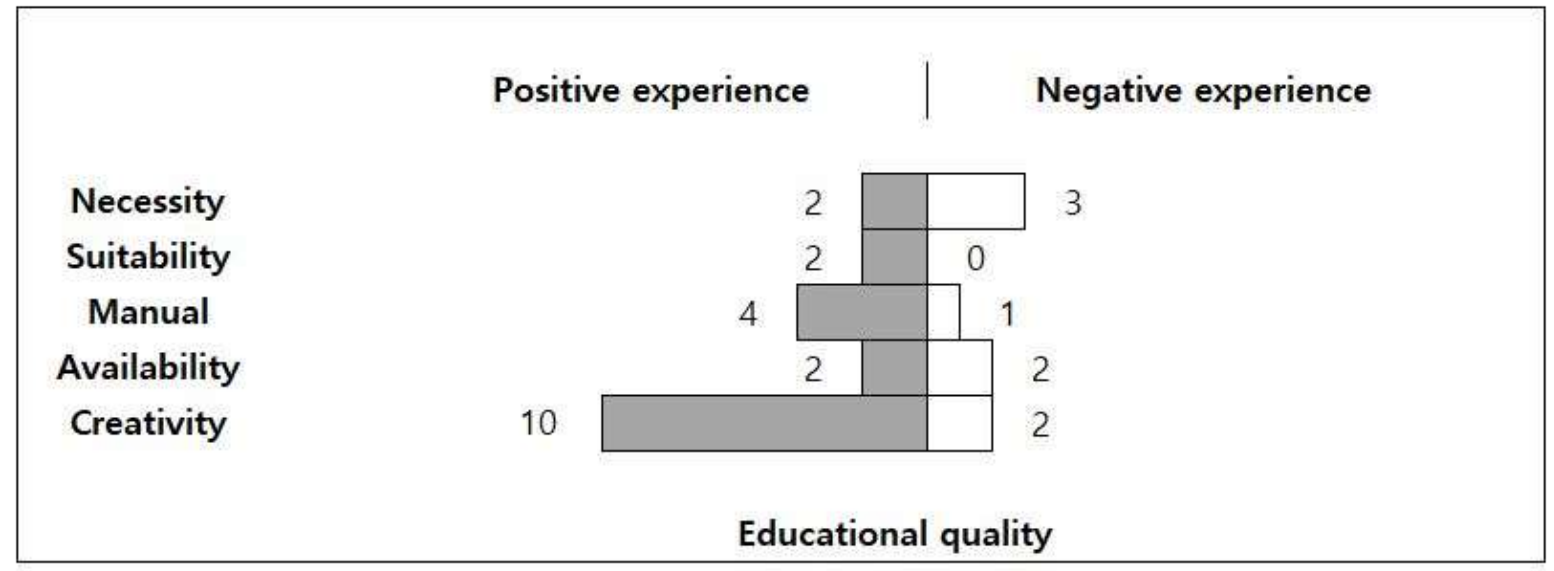

Figure 2. Educational Quality

\subsubsection{Service Quality}

Educational services can be said 'providing activities' from the school's point of view, and 'the sum of experiences' from the student's point of view. Based on a preceding study, the characteristics of educational service quality are similar to the service in general sense [21], and that education is a kind of 
service and the quality of education can be evaluated using a service quality evaluation tool [16].

This study also aims to measure the service quality of ETA using SERVQUAL. In general, educational services covers the quality of education, relationship with professors, student relations, curriculum, administrative facilities, and etc. However, this study deals with the quality of service as a whole in terms of the purchase and delivery of teaching aids for companies that manufacture and sell ETA.

A. Parasuraman, Valarie A. Zeltham I, \& Leonard L Berry conducted a study on consumers' perception of service quality through exploratory research (focus group and in-depth executive interviews) [15]. According to this study, it has been revealed that even though there are different types of services, there are 10 criteria by which consumers shape their expectations and perceptions about services, and the initial 10 dimensions and 97 items were then reduced to 5 dimensions and 22 items, and these are : Tangibility, Reliability, Responsiveness, Assurance, Empathy [17, 22].

According to the CIT results, about $93 \%$ of elementary school teachers buy ETA online. Therefore, among the five dimensions of SERVQUAL, Tangibility was excluded because it has no measurement meaning, and Accessibility indicator was added because many teachers valued the convenience in purchasing ETA.

Based on the facts stated above, and with regards to this study, the service quality is then categorized into five namely: Reliability, Responsiveness, Assurance, Empathy, and Accessibility.

[Figure 3] shows the results of the 142 core events which appeared in the survey using the CIT, that was arranged accordingly to match with the five (5) categories stated above. As a result, only Reliability and Accessibility came out and no other categories found. Through this, it can be inferred that teachers are usually more interested in the convenience of purchasing a product and also gives importance to the reliability of the company.

In this study, the hypothesis below tries to be established and verified based on the preceding facts stated above.

H 3: Service quality will have a positive (+) effect on teacher's satisfaction.

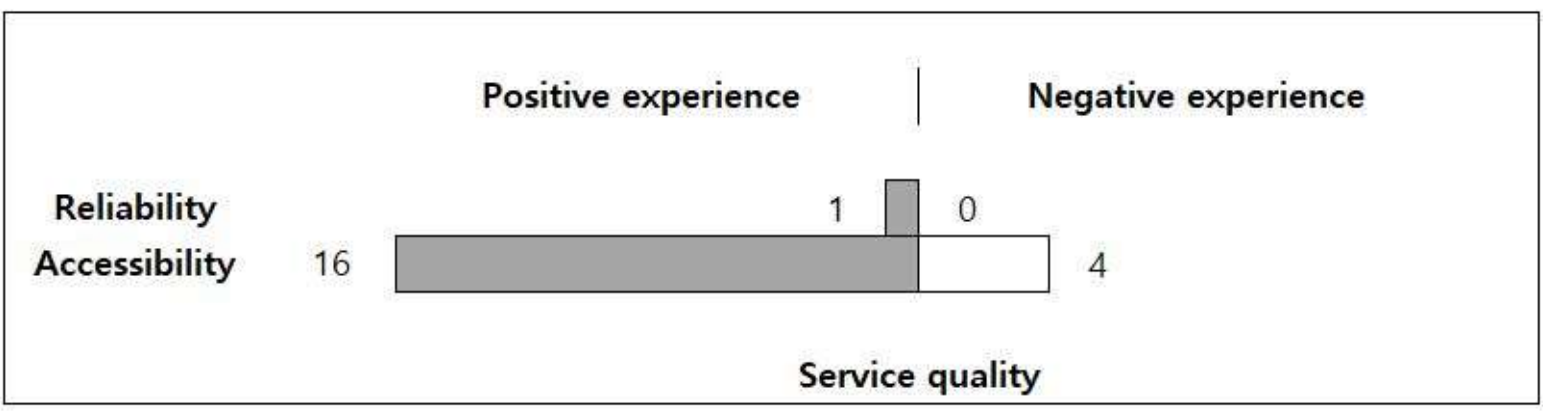

Figure 3. Service Quality

\subsubsection{Teacher's Satisfaction and Repurchase Intention}

Most of the research on teacher satisfaction deals with the job satisfaction of teachers for the teaching profession. However, this study is not intended to measure the teachers' job satisfaction. The purpose of this study is to study the teachers' satisfaction with regards to the overall process, from purchasing the ETA to using it as an educational aid. This can also be said as closer to the concept of general customer satisfaction.

Customer satisfaction can be defined from several perspectives, and Oliver said that the evaluation of the surprise inherent in the purchase or consumption experience of a product can be understood as satisfaction. In addition, the psychological state that happens when consumers' unconfirmed expectations and consumption experiences are combined with the consumers' previous experiences is also called satisfaction [23]. Therefore, satisfaction can be expressed as the consumer's evaluation of the perceived difference between expectations that consumers feel about the products before use and the expectations they feel about the products after use.

Most of the repurchase intention in education-related research has meanings such as readmission intention and word of mouth effect. Thus, in this study, the repurchase intention is defined as the teachers' intention (or word of mouth) of purchasing again, and recommend ETA to the teachers around them.

According to the preceding studies [24], it suggested that if there's a better experience on using a certain product, there will be a higher intention to repurchase it or to recommend it to others. Therefore, with regards to this study, it can be expected that the better the experience that the teachers had in using the ETA, the higher the repurchase intention there will be.

In this study, the hypothesis below tries to be established and verified based on the preceding 
statements.

H 4: Teacher's satisfaction will have a positive $(+)$ effect on repurchase intention.

\subsection{Research model}

Based on the CIT which was conducted first, latent variable items for measurement was established. Moreover, with reference to prior research and CIT, three categories were decided: product quality (PQ), educational quality (EQ), and service quality (SQ). Also, an early research model was set up to measure the effect of this item on teacher's satisfaction (S) and repurchase intention (RI). The measurement variables of Product Quality (PQ) was then classified as Safety (PQ-A), Functionality (PQ-B), Convenience $(\mathrm{PQ}-\mathrm{C})$, Design (PQ-D), Economic (PQ-E), Management (PQ-F). On the other hand, the measurement variables of Educational Quality (EQ) was classified as Necessity (EQ-A), Suitability (EQ-B), Manual (EQ-C), Availability (EQ-D), and Creativity (EQ-E). Meanwhile, the measurement variables of Service Quality (SQ) was classified as Reliability (SQ-B), Responsiveness (SQ-C), Assurance (SQ-D), Empathy (SQ-E), and Accessibility (SQ-F). However, there was a classification 'Tangible' in the service quality, but it was removed because it was not meaningful as a result of the second questionnaire. Teacher's satisfaction (S) was classified as a measurement variable, such as S-A to D, and repurchase intention (RI) was classified as RI-A. Then based on above content, a questionnaire was produced and the second survey was conducted.

After the second questionnaire has been conducted, the above measurement variables and latent variables required some modifications. As a result of an analysis using Smart PLS (3.3.2), some measurement variables and latent variables were removed if the Outer loading was lower than 0.7. For example, items of Responsiveness and Empathy, which are latent variables in the Service Quality segment, were removed. To illustrate this, the final research model as shown in [Figure 4] was made.

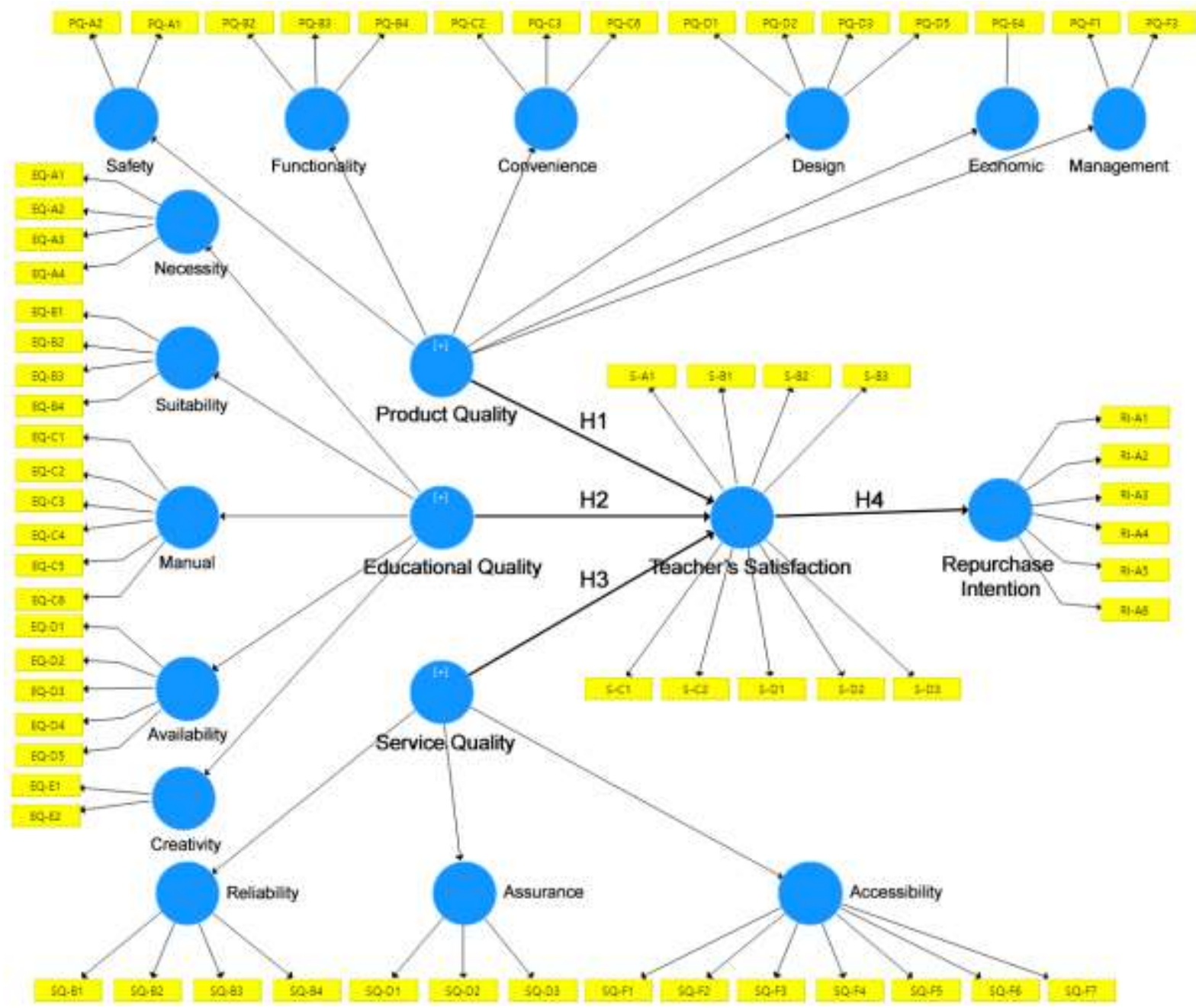

Figure 4. Research Model

\subsection{Data collection and Analysis method}


The subject of this study is limited to elementary school teachers. Whereas, in elementary schools, compared to the teachers in the middle school and high school, there are only a few teachers who majored in Science. Unlike middle and high school, there are not many teachers who majored in science in elementary schools, and because they have to teach all subjects, there are many difficulties and lack of expertise. For this reason, elementary teachers need more ETA that can be highly utilized.

Based on the first CIT results and prior studies [14, 16, 17, 18, 19], key latent variables such as Product Quality, Educational Quality, Service Quality, Teacher's Satisfaction, and Repurchase Intention was extracted. The 2nd questionnaire consisted of a total of 97 questions, including five key variables, demographic items, and basic questions on purchasing and using ETA. Questions about the measurement variables were used the Likert 5-point scale. The survey was conducted online from May 5 to May 12, 2020, and 73 questionnaires were collected.

The empirical analysis of this study was conducted using the Smart PLS (3.3.2) statistical program. PLS-SEM (Partial Least Squares - Structural Equation Modeling) is suitable for this study because it is closer to prediction than theoretical verification, and shows high statistical verification power even in small samples, and has high statistical verification power even when the model is complex [26].

The first step conducted was the analysis of survey subjects that has been analyzed through demographic data. Next is the PLS-SEM evaluation, wherein the Outer model is evaluated by applying internal consistency, reliability, Convergent validity, and Discriminant validity. Finally, the Inner model is evaluated by applying Multicollinearity, Coefficient of Determination, Effect Size, and Predictive Relevance [27].

\section{Results}

\subsection{Demographic characteristics of Sample}

Demographic characteristics of this study is shown in [Table 1].

Table 1. Demographic characteristics $(\mathrm{N}=73)$

\begin{tabular}{|l|l|l|}
\hline \multicolumn{2}{|l|}{ Item } & N (\%) \\
\hline \hline \multirow{4}{*}{ Gender } & Male & $23(32)$ \\
\cline { 2 - 3 } & Female & $50(68)$ \\
\hline \hline \multirow{3}{*}{$\begin{array}{l}\text { Age } \\
\text { group }\end{array}$} & $20 \mathrm{~s}$ & $7(10)$ \\
\cline { 2 - 3 } & $30 \mathrm{~s}$ & $10(14)$ \\
\cline { 2 - 3 } & $40 \mathrm{~s}$ & $28(38)$ \\
\cline { 2 - 3 } & $50 \mathrm{~s}$ & $26(35)$ \\
\cline { 2 - 3 } & Over 60s & $2(3)$ \\
\hline
\end{tabular}

\begin{tabular}{|l|l|l|}
\hline \multicolumn{2}{|l|}{ Item } & N (\%) \\
\hline \hline \multirow{4}{*}{$\begin{array}{l}\text { Work } \\
\text { experience }\end{array}$} & Less than 1 year & $1(1)$ \\
\cline { 2 - 3 } & 1 to 10 years & $13(17)$ \\
\cline { 2 - 3 } & 11 to 20 years & $22(30)$ \\
\cline { 2 - 3 } & 21 to 30 years & $34(48)$ \\
\cline { 2 - 3 } Work place & 31 to 40 years & $3(4)$ \\
\cline { 2 - 3 } & Over 41 years & $0(0)$ \\
\hline \hline \multirow{4}{*}{ Susan } & $4(6)$ \\
\cline { 2 - 3 } & Geoul & $3(4)$ \\
\cline { 2 - 3 } & Gyeonggi & $66(90)$ \\
\hline
\end{tabular}

The subject of this study are elementary school teachers. Most of the respondents are in their 40s and above, and teachers with over 10 years of work experience. It was intended to be conducted mainly to the teachers from the Gyeonggi area, but there are also some teachers who are from Seoul and Busan.

\subsection{Measurement of Outer Model}

\subsubsection{Internal consistency reliability}

Internal Consistency Reliability is a method of measuring reliability when multiple measurement variables are used to measure the same latent variable. The criteria for evaluating Internal Consistency Reliability include Cronbach's Alpha, Dijkstra-Henseler's rho, CR (Composite Reliability), etc [27,29].

Table 2. Internal Consistency Reliability

\begin{tabular}{|l|l|l|l|}
\hline & Cronbach's Alpha & rho_A & Composite Reliability \\
\hline Teacher's Satisfaction & 0.933 & 0.937 & 0.943 \\
\hline
\end{tabular}




\begin{tabular}{|l|l|l|l|}
\hline Educational Quality & 0.963 & 0.964 & 0.966 \\
\hline Service Quality & 0.927 & 0.929 & 0.937 \\
\hline Repurchase Intention & 0.929 & 0.952 & 0.945 \\
\hline Product Quality & 0.942 & 0.945 & 0.949 \\
\hline
\end{tabular}

When the Cronbach's alpha value is 0.7 or higher, it means that it shows desirable reliability [28]. As shown in [Table 2], the variables of this study are all higher than 0.9 , thus showing high reliability. Likewise, when the Rho and CR values are 0.7 or higher, it is also considered to have a desirable reliability $[27,29]$. In this study, since the Rho and CR values of all variables are more than 0.7 , it can be considered to have internal consistency reliability.

\subsubsection{Convergent validity}

Convergent validity means that there must be a high correlation between the results of measuring the same latent variable by different measurement methods. As evaluation criteria, Outer Loading Relevance, Indicator Reliability, and AVE (Average Variance Extracted) are used [27].

In this study, since there are many measurement variables, it has been difficult to include the measurement result tables of Outer Loading Relevance and Indicator Reliability in this paper. However, to be able to check the measurement table of Outer Loading Relevance and Indicator Reliability, kindly refer to this link: https://1drv.ms/x/s!AspakG4TJsqCkQyrsTgI3otjKzGF?e=N9CA2f. When Outer Loading Relevance is 0.7 or more, and Indicator Reliability is 0.5 or more, it indicates desirable Convergent validity [27]. On the table presented in the link, it can be observed that there is a total of 65 remaining measurement variables after removing the measurement variables with Outer Loading Value of less than 0.4 , and among the 65 measurement variables, there are 16 measurement variables that have a value of $0.6 \sim 0.7$. However, it was not removed. Based on the prior studies, the measurement variable may be maintained if the CR or AVE does not increase to a desirable value when the variables are removed [30].

If the AVE (Average Variance Extracted) value is 0.5 or more, it can be considered to have a desirable Convergent validity. This means that the latent variable accounts for more than half of the variance of the measurement variables [25]. In this study, all latent variables have a value of 0.5 or more, therefore, it can be said that it does have a desirable convergent validity [Table 3].

Table 3. Convergent Validity

\begin{tabular}{|l|l|}
\hline Variables & AVE \\
\hline Product Quality & 0.558 \\
\hline Educational Quality & 0.577 \\
\hline Service Quality & 0.516 \\
\hline Teacher's Satisfaction & 0.650 \\
\hline Repurchase Intention & 0.742 \\
\hline
\end{tabular}

\subsubsection{Discriminant validity}

Discriminant validity refers to the degree at which a latent variable can be distinguished well from another latent variable [27]. In this study, Discriminant validity is measured using Cross Loadings and HTMT (Heterotrait-monotrait ratio).

Cross Loadings Analysis is a kind of exploratory factor analysis and is a method of evaluating Discriminant validity with Outer Loading Relevance and Cross Loadings [27]. If Outer Loading Relevance exceeds Cross Loadings, then, Discriminant Validity exists. For example, referring to the Teacher's Satisfaction variable in [Table 4], it can be seen that the colored Outer Loading Relevance values exceeds all of the Cross Loadings values of other variables.

All variables in this study was determined to have 'Discriminant validity'. Kindly check the result table for all 'Cross Loadings' by referring to this link: https://1drv.ms/x/s!AspakG4TJsqCkQyrsTgI3otjKzGF?e=N9CA2f. (please see Cross Loadings sheet) 
Table 4. Cross Loadings Analysis Example

\begin{tabular}{|l|l|l|l|l|l|l|}
\hline \multirow{4}{*}{$\begin{array}{l}\text { Latent } \\
\text { Variable }\end{array}$} & $\begin{array}{l}\text { Measured } \\
\text { Variable }\end{array}$ & $\begin{array}{l}\text { Teacher's } \\
\text { Satisfaction } \\
(\mathrm{S})\end{array}$ & $\begin{array}{l}\text { Educational } \\
\text { Quality } \\
(\mathrm{EQ})\end{array}$ & $\begin{array}{l}\text { Service } \\
\text { Quality } \\
(\mathrm{SQ})\end{array}$ & $\begin{array}{l}\text { Repurchase } \\
\text { Intention } \\
(\mathrm{RI})\end{array}$ & $\begin{array}{l}\text { Product } \\
\text { Quality } \\
\text { (PQ) }\end{array}$ \\
\hline \multirow{5}{*}{\begin{tabular}{l}
\multirow{4}{*}{$\begin{array}{l}\text { Seacher's } \\
\text { Satisfaction }\end{array}$} \\
\cline { 2 - 7 }
\end{tabular}} & S-A1 & 0.807 & 0.631 & 0.616 & 0.517 & 0.629 \\
\cline { 2 - 7 } & S-B1 & 0.767 & 0.542 & 0.492 & 0.432 & 0.572 \\
\cline { 2 - 7 } & S-B2 & 0.829 & 0.729 & 0.677 & 0.536 & 0.618 \\
\cline { 2 - 7 } & S-C1 & 0.805 & 0.640 & 0.643 & 0.501 & 0.566 \\
\cline { 2 - 7 } & S-C2 & 0.850 & 0.641 & 0.693 & 0.586 & 0.569 \\
\cline { 2 - 7 } & S-D1 & 0.726 & 0.507 & 0.650 & 0.408 & 0.411 \\
\cline { 2 - 7 } & S-D2 & 0.806 & 0.696 & 0.558 & 0.685 & 0.566 \\
\cline { 2 - 7 } & S-D3 & 0.830 & 0.667 & 0.563 & 0.715 & 0.631 \\
\hline
\end{tabular}

HTMT (Heterotrait-monotrait ratio) is one of the discriminant validity evaluation criterions. In this study, HTMT was measured using 'Bootstrapping confidence interval', which is considered as the freest criterion. This concludes that there is discriminant validity when 1 is not included in the confidence interval [31].

The measurement results of this study are shown in [Table 5]. Discriminant validity can be seen as being secured because there is no case that 1 is included between the lower limit (2.5\%) and the upper limit (97.5\%).

Table 5. HTMT (Heterotrait-monotrait ratio)

\begin{tabular}{|l|l|l|l|l|l|}
\hline & Original Sample (0) & Sample Mean (M) & Bias & $2.50 \%$ & $97.50 \%$ \\
\hline $\mathrm{S} \rightarrow \mathrm{RI}$ & 0.726 & 0.734 & 0.007 & $\mathbf{0 . 5 9 1}$ & $\mathbf{0 . 8 2 2}$ \\
\hline $\mathrm{EQ} \rightarrow \mathrm{S}$ & 0.455 & 0.446 & -0.009 & $\mathbf{0 . 2 0 6}$ & $\mathbf{0 . 6 7 6}$ \\
\hline $\mathrm{SQ} \rightarrow \mathrm{S}$ & 0.314 & 0.325 & 0.011 & $\mathbf{0 . 1 2 6}$ & $\mathbf{0 . 4 9 6}$ \\
\hline $\mathrm{PQ} \rightarrow \mathrm{S}$ & 0.205 & 0.202 & -0.003 & $\mathbf{0 . 0 2 5}$ & $\mathbf{0 . 4 3 3}$ \\
\hline
\end{tabular}

\subsection{Measurement of Inner Model}

As a result of the evaluation of the outer model, it has been established that the reliability and validity of the measurement and latent variables existed. Subsequently, it is necessary to determine the research model and conduct the Inner Model evaluation to confirm whether it is an appropriate model. Since PLS-SEM has not yet been developed as an applicable goodness of fit index, separate evaluation criteria for evaluating the Inner Model is applied, and this will be the Multicollinearity, Coefficient of Determination (R2), Effect size (f2), and Predictive Relevance (Q2) [27].

Multicollinearity is described as the Inner VIF Values of Inner Model. If this value is less than 5, it means that there is no multicollinearity between the latent variables. The results of this are shown in [Table 6]. This table shows that there is no multicollinearity since all values are less than 5.

On the other hand, the effect size represents the degree to which exogenous latent variables contribute to Coefficient of Determination of endogenous latent variables. 0.15 or more means medium while 0.35 or more means large effect size [27]. The measured values of this are also shown in [Table 6]. This table shows that except for Product quality, everything else has a relatively high effect size.

Coefficient of Determination can be interpreted to mean the explanatory power of the model. It has a 
value of 0 to 1 , and the closer to 1 , the higher the explanatory power [27]. The measured values of the Coefficient of Determination are also reflected in [Table 6] and it shows that there is a relatively high explanatory power.

Table 6. Evaluation of Inner Model

\begin{tabular}{|c|c|c|c|c|c|c|}
\hline & \multicolumn{2}{|c|}{ Teacher's Satisfaction } & \multicolumn{2}{|c|}{ Repurchase Intention } & \multicolumn{2}{|c|}{ Doefficient of } \\
\hline & $\begin{array}{l}\text { Inner } \\
\text { VIF Values } \\
\text { (Multicollinearity } \\
\text { ) }\end{array}$ & $\begin{array}{l}\text { Effect } \\
\text { size }\left(\mathrm{f}^{2}\right)\end{array}$ & $\begin{array}{l}\text { Inner } \\
\text { VIF } \quad \text { Values } \\
\text { (Multicollinearity } \\
\text { ) }\end{array}$ & $\begin{array}{l}\text { Effect size } \\
\left(f^{2}\right)\end{array}$ & R Square & $\begin{array}{l}\text { R Square } \\
\text { Adjusted }\end{array}$ \\
\hline $\begin{array}{l}\text { Teacher's } \\
\text { Satisfaction }\end{array}$ & & & 1 & 1.116 & 0.742 & 0.731 \\
\hline $\begin{array}{l}\text { Educational } \\
\text { Quality }\end{array}$ & 2.267 & 0.354 & & & & \\
\hline $\begin{array}{l}\text { Service } \\
\text { Quality }\end{array}$ & 1.923 & 0.199 & & & & \\
\hline $\begin{array}{l}\text { Repurchase } \\
\text { Intention }\end{array}$ & & & & & 0.527 & 0.521 \\
\hline $\begin{array}{l}\text { Product } \\
\text { Quality }\end{array}$ & 2.087 & 0.078 & & & & \\
\hline
\end{tabular}

Predictive Relevance is an evaluation criterion that can only determine how much predictive relevance the Inner Model has for a specific latent variable, and this can be obtained through the Blindfolding procedure. If $Q^{2}$ is greater than 0 , it can be determined that the Inner model has predictive relevance for a specific latent variable [27].

The Predictive Relevance is reflected on [Table 7], and it shows that the teacher's satisfaction and repurchase intention have Predictive Relevance.

Table 7. Predictive Relevance

\begin{tabular}{|l|l|l|l|}
\hline & SSO & SSE & $Q^{2}(=1-$ SSE/SSO $)$ \\
\hline Teacher's Satisfaction & 657 & 351.362 & $\mathbf{0 . 4 6 5}$ \\
\hline Educational Quality & 1533 & 1533 & \\
\hline Service Quality & 1022 & 1022 & \\
\hline Repurchase Intention & 438 & 272.888 & $\mathbf{0 . 3 7 7}$ \\
\hline Product Quality & 1095 & 1095 & \\
\hline
\end{tabular}

\subsection{Hypothesis testing}

The conclusions for this study was summarized and is reflected on [Table 8] and [Figure 5].

At the significant level of 0.05 , all $\mathrm{T}$ values are greater than the critical value (1.96), and all $\mathrm{P}$ values are less than the significant level of 0.05 . With reference to this, all research hypotheses were adopted, and it can be said that product quality, educational quality, and service quality all have a positive $(+)$ effect on teacher's satisfaction, and that teacher's satisfaction also has a positive $(+)$ effect on repurchase 
intention. However, in the case of educational quality, it can be observed that the significant level is somewhat higher than 0.05 , which means that the educational quality has quite a less impact on teacher's satisfaction than the other variables.

Table 8. Hypothesis Testing

\begin{tabular}{|l|l|l|l|l|l|}
\hline & Original Sample & T Statistics & P Values & $\begin{array}{l}\text { significance } \\
(\mathrm{p}<0.05)\end{array}$ & Result \\
\hline H1: $\mathrm{PQ} \rightarrow \mathrm{S}$ & 0.205 & 2.027 & $\mathbf{0 . 0 4 3}$ & Yes & adoption \\
\hline $\mathrm{H} 2: \mathrm{EQ} \rightarrow \mathrm{S}$ & 0.455 & 3.702 & $\mathbf{0 . 0 0 0}$ & Yes & adoption \\
\hline $\mathrm{H} 3: \mathrm{SQ} \rightarrow \mathrm{S}$ & 0.314 & 3.267 & $\mathbf{0 . 0 0 1}$ & Yes & adoption \\
\hline $\mathrm{H} 4: \mathrm{S} \rightarrow \mathrm{RI}$ & 0.726 & 12.418 & $\mathbf{0 . 0 0 0}$ & Yes & adoption \\
\hline
\end{tabular}

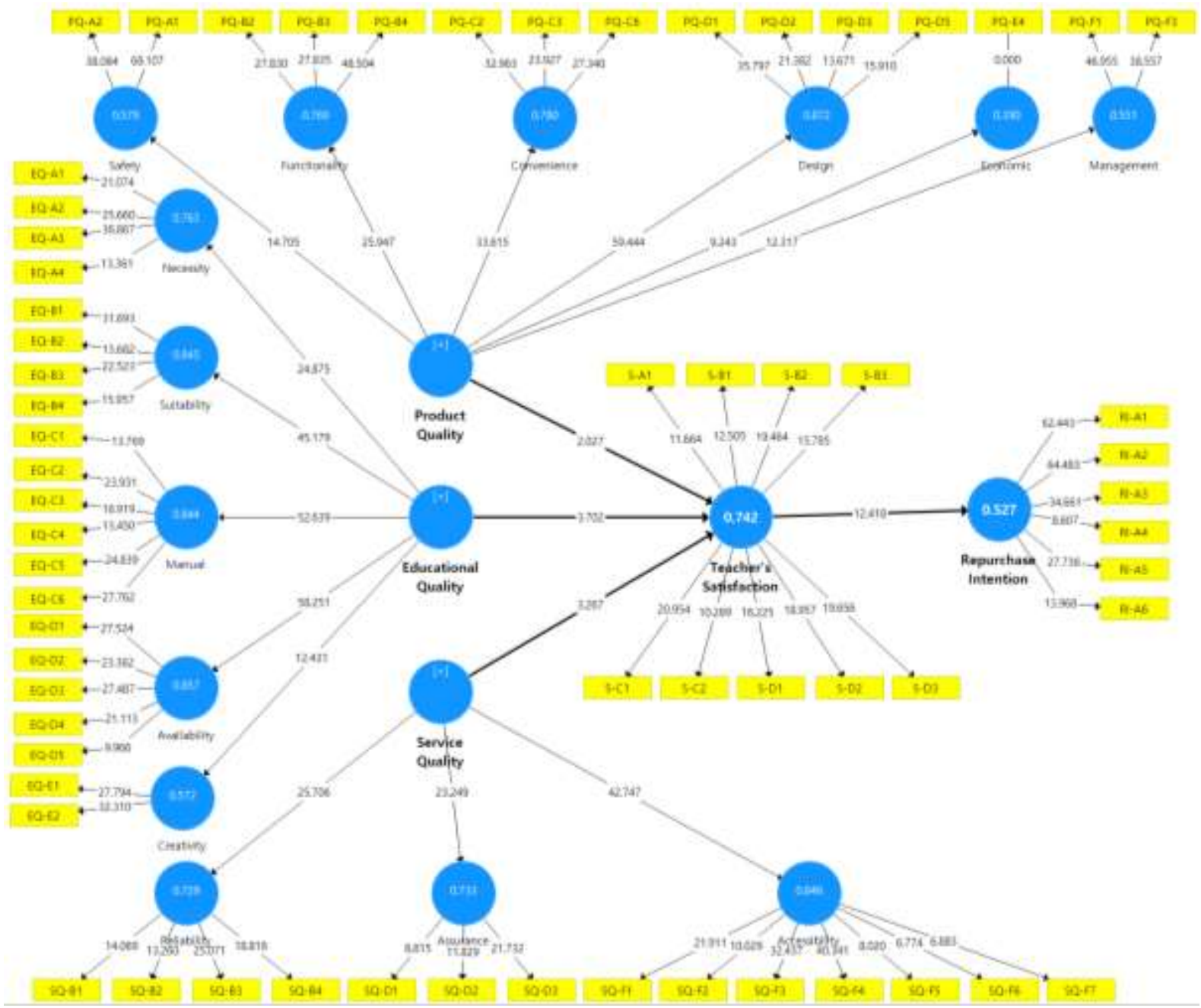

Figure 5. PLS-SEM Analysis Result

\section{Conclusions}

This paper studied how elementary school teachers consider 'Experimental (practice) Teaching Aids (ETA) as useful in the conduct of their classes and their satisfaction throughout the entire process from purchasing to using and until repurchasing the ETA.

As a result of CIT, teachers had a lot of negative feelings about functionality related to Product Quality, and a lot of positive feelings about Convenience. Although there were many dissatisfactions with the Product Quality, but it can be inferred that it is composed of kits and teachers use it comfortably in class. In terms of Educational quality, most teachers responded positively to the Creativity item. Teachers said 
that if they use ETA to conduct classes, the children's participation is higher and they participate in activities with fun. This shows the same results as prior studies that the use of kits induces more active participation in students. In the accessibility part of Service Quality, there were more answers to positive experiences. This means that teachers do not have much difficulty in purchasing and using ETA.

All research hypotheses were adopted through empirical analysis. First of all, Product Quality was analyzed to have a positive (+) effect on teacher's satisfaction. Looking at the first CIT results, teachers had a lot of dissatisfaction with the quality of the product, which can be inferred to some extent by looking at the actual analysis results such as $p$ value $(0.043, p<0.05)$ and $t$ value. However, from the fact that the hypothesis has not been rejected, it can be seen that many teachers were satisfied with the quality of the product compared to the price, and verified that besides the quality, 'easy to use in class', 'safe materials and packaging' and 'easy to manage' worked effectively for teachers.

Second, it has been analyzed that education quality had a positive (+) effect on teacher's satisfaction. Most teachers recognized that ETA was suitable in achieving the learning goals, and that it would help induce the interest and creativity of the children in the class.

Third, this study was able to analyze that Service Quality has a positive (+) effect on teacher's satisfaction. There are five (5) dimensions of SERVQUAL but Tangibility was excluded, and Accessibility was added in the conduct of this analysis. As a result, the analysis was conducted with the variables Reliability, Assurance, and Accessibility. Most teachers showed satisfaction with Accessibility and Reliability, in that they can easily purchase the products online and receive friendly counseling and after sales service (A/S). This is also consistent with the CIT results. Finally, it was analyzed that Teacher's Satisfaction had a positive (+) effect on Repurchase Intention. Of course, if teachers have a good experience and good results by using ETA, the Repurchase Intention will naturally increase. This was also proved by several other prior studies.

The implications of this study are the following:

Foremost, this study used the PLS-SEM technique for hypothesis testing. This statistical technique is not that widely used in school related studies, however, it could be utilized to have a potential use to various school related studies in the future. Second, this study can give application guidance to co mpanies that manufacture ETA and contents. Since there's only a few researches on ETA that is used in schools, it has been difficult for companies to properly grasp the characteristics of products and contents that is needed by the schools and the teachers. This study can be used as a basic data for the development and distribution of new products and contents for companies that manufacture ETA and contents. In addition to this, the fact that there are few studies on ETA used in schools means that teachers are not knowing how ETA are being used. Thus, this study can give teachers insight about how to use ETA in the educational field by providing statistical data on the use of teaching aids. Lastly, this study focused on elementary school teachers, but the middle school and high school teachers also use various ETA to conduct classes, however, it is difficult to find such research related to the use of ETA by the middle school and high school teachers. So, one of the important implications of this study is that it can serve as a basis for research about the use of ETA in the middle schools and high schools.

Although this study is one of the rare studies on ETA that is used in schools, it also has its limitations. First is the limitation on data collection. Due to the COVID-19 pandemic, the survey was conducted through online because it was difficult to conduct face-to-face interview with the teachers, and only a few samples were obtained. Another is the local limitations. All samples collected were concentrated in the Gyeonggi area. However, in the future, it will be anticipated that more accurate results will be obtained if the number of samples has been increased and the research is conducted by expanding to regions nationwide.

\section{Acknowledgements}

This research was financially supported by Hansung University.

\section{References}

[1] Howells, K. "The future of education and skills: education 2030: the future we want." (2018).

[2] Dickerson, Daniel, Matthew Clark, Karen Dawkins, and Cathy Horne. "Using science kits to construct content understandings in elementary schools." Journal of Elementary Science Education 18, no. 1 (2006): 43-56.

[3] Sherman, Ann, and A. Leo MacDonald. "The Use of Science Kits in the Professional Development of Rural Elementary School Teachers." Science Education Review 7, no. 3 (2008): 91-105.

[4] National Research Council. Inquiry and the national science education standards: A guide for teaching and learning. National Academies Press, 2000. 
[5] Houston, Linda Scott, Barry J. Fraser, and Cynthia E. Ledbetter. "An evaluation of elementary school science kits in terms of classroom environment and student attitudes." Journal of Elementary Science Education 20, no. 4 (2008): 29-47.

[6] Rubino, Antonio N. "Effects of Science Kits on Attitudes and Accomplishment of Students in Science." (1994).

[7] Gennaro, Eugene, and Frances Lawrenz. "The effectiveness of take-home science kits at the elementary level." Journal of Research in Science Teaching 29, no. 9 (1992): 985-994.

[8] Şengül, Seda Hilal, Gülcan Çetin, and G. Ü. R. Hülya. "The primary school science teachers' problems in science teaching." Journal of Turkish Science Education 5, no. 3 (2008): 82-88.

[9] Korean Consumer Agency. "Survey on Safety Status of Science Experiment Aids of Elementary School - $\quad$ Focused on Online Shopping Mall Sales." safety report. (2019) http://www.dbpia.co.kr/journal/articleDetail?nodeId=NODE09322076

[10] Hwang, Seo-mok, WON, Hyo-Heon. "A Study on the Factors of Dissatisfaction and Relative Severity of Lifelong Education Programs Using Critical Incident Technique (CIT), The Korean Society Fishries and Sciences Education." JOURNAL OF FISHRIES AND MARINE SCIENCES EDUCATION 31(1), (2019): 324-335(12 pages) http://www.dbpia.co.kr/journal/articleDetail?nodeId=NODE07616047

[11] Flanagan, John C. "The critical incident technique." Psychological bulletin 51, no. 4 (1954): 327.

[12] Bitner, Mary Jo, Bernard H. Booms, and Mary Stanfield Tetreault. "The service encounter: diagnosing favorable and unfavorable incidents." Journal of marketing 54, no. 1 (1990): 71-84.

[13] Sherman, Ann, and Leo MacDonald. "Pre-service teachers' experiences with a science education module." Journal of Science Teacher Education 18, no. 4 (2007): 525-541.

[14] King, Ken, Lee Shumow, and Stephanie Lietz. "Science education in an urban elementary school: Case studies of teacher beliefs and classroom practices." Science education 85, no. 2 (2001): 89-110.

[15] Parasuraman, Anantharanthan, Valarie A. Zeithaml, and Leonard L. Berry. "A conceptual model of service quality and its implications for future research." Journal of marketing 49, no. 4 (1985): 41-50.

[16] Han, Sang-Doll. "Service Quality Assessment with Structural Equation-Mainly on Education Quality". The Graduate School, Doctoral dissertation. Catholic University of Daegu. (2009). https://academic.naver.com/article.naver?doc_id=17345209

[17] Choi, D. C., and K. Oh Lee. "A Study on the Model Build-Up for Educational Service Marketing of University." Journal of Korean Academy of Marketing Science 6, no. 1 (2000): 339-366.

[18] Beon, Hee-Jean. "A Study on the Development of Experiential DIY Design Teaching Tools." The $\begin{array}{llllll}\text { Treatise on } & \text { (2018): } & \text { 47-57. }\end{array}$ http://www.papersearch.net/thesis/article.asp?KEY=3641136

[19] Jeon, HyeongKi, and Yungsik Kim. "Development of the Evaluation Criteria of the Physical Computing Based Learning Tools for SW Education in the 2015 Revised National Curriculum for Elementary Education." The Journal of Korean Association of Computer Education 21, no. 5 (2018): 37-48.

[20] Nam, Hyun-Wook. "Analysis of Electronic Kits for Elementary School Student." The Korean $\begin{array}{lllll}\text { Association of } & \text { Practical }\end{array}$ http://www.dbpia.co.kr/journal/articleDetail?nodeId=NODE06072119

[21] Park, Kun-Hee. "The influence of perceived educational service quality on students satisfaction and relationship marketing of students majoring in dance." Korean J. Phys. Educ 48, no. 6 (2009): 463-473.

[22] Parasuraman, Ananthanarayanan, Valarie A. Zeithaml, and Leonard L. Berry. "Servqual: A multiple-item scale for measuring consumer perc." Journal of retailing 64, no. 1 (1988): 12.

[23] Oliver, Richard L. "Measurement and evaluation of satisfaction processes in retail settings." Journal of retailing (1981).

[24] Hwang, Heejoong. "The Effect of Education Service Quality on the Education Service Repurchase Intention: Education Service Price Fairness as Mediator." Korean Journal of Business Administration 25, no. 1 (2012): 1-19.

[25] Hair, Joe F., Christian M. Ringle, and Marko Sarstedt. "PLS-SEM: Indeed a silver bullet." Journal of Marketing theory and Practice 19, no. 2 (2011): 139-152.

[26] Chin, Wynne W. "How to write up and report PLS analyses." In Handbook of partial least squares, pp. 655-690. Springer, Berlin, Heidelberg, 2010.

[27] Shur, Won-Kyo. SmartPLS 3.0. Partial Least Squares Structural Equation Modeling (PLSSEM) with SmartPLS 3.0, SPSS, G* Power. Cheongram press. 2018. 
[28] Cronbach, Lee J. "Coefficient alpha and the internal structure of tests." psychometrika 16, no. 3 (1951): 297-334.

[29] Dijkstra, Theo K., and Jörg Henseler. "Consistent partial least squares path modeling." MIS quarterly 39, no. 2 (2015).

[30] Bagozzi, Richard P., Youjae Yi, and Lynn W. Phillips. "Assessing construct validity in organizational research." Administrative science quarterly (1991): 421-458.

[31] Shaffer, Juliet Popper. "Multiple hypothesis testing." Annual review of psychology 46, no. 1 (1995): 561-584. 